UCRL-JC-121232

PREPRINT

\title{
Localized Dryout: An Approach for Managing the Thermal Hydrological Effects of Decay Heat at Yucca Mountain
}

\author{
Thomas A. Buscheck \\ John J. Nitao \\ Lawrence D. Ramspott
}

RECEIVED

MAR 289996

OSTI

This paper was prepared for submittal to the

Materials Research Society

Boston, $M A$

November 27 - December 1, 1995

November 1995

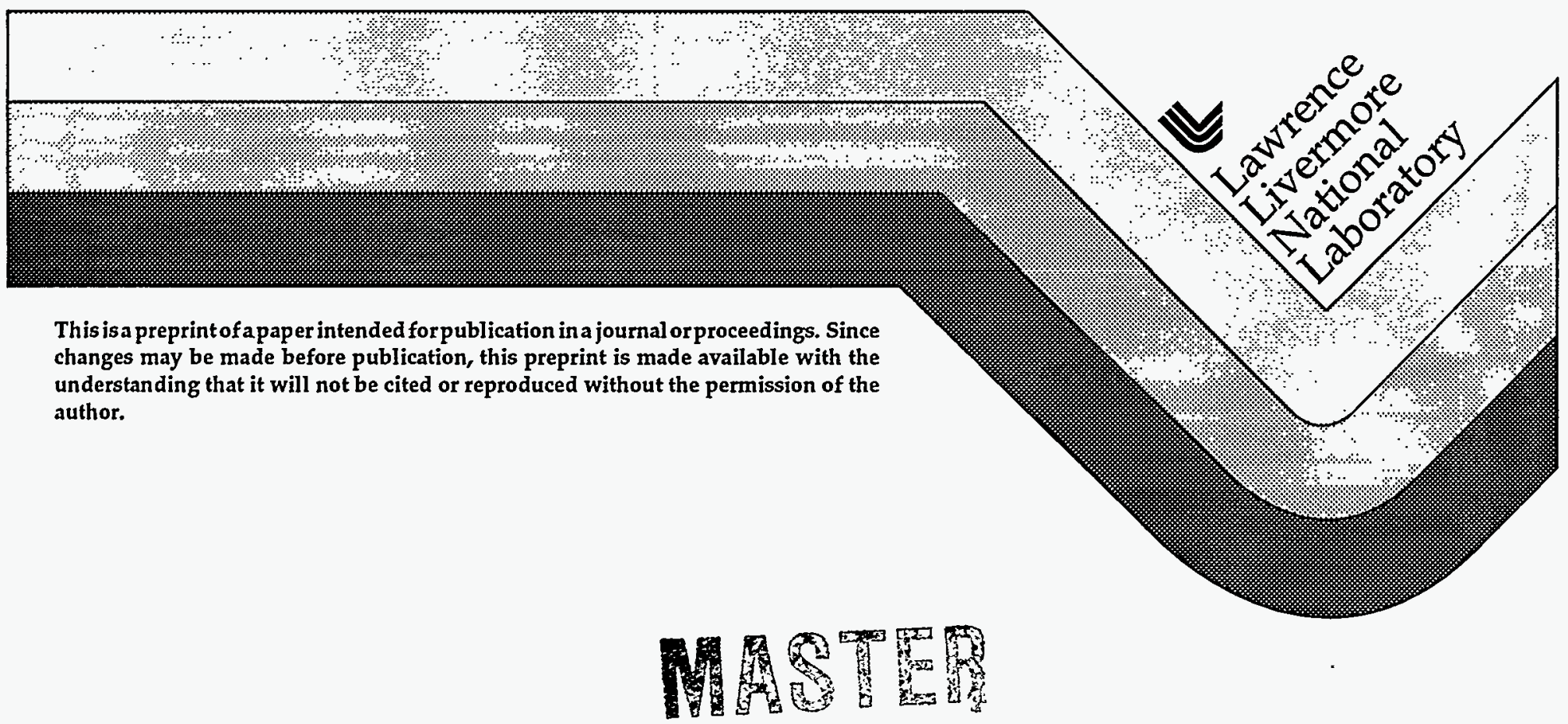




\section{DISCLAIMER}

This document was prepared as an account of work sponsored by an agency of the United States Government. Neither the United Stales Government nor the University of California nor any of their employees, makes any warranty, express or implied, or assumes anylegal liability or responsibility for the accuracy, completeness, or usefulness of any information, apparatus, product, or process disdosed, or represents that its use would not infringe privately owmed rights. Reference herein to any speciliccommercial products, process, or service by trade name, trademark, manufacturer, or otherwise, does not necessarily constilute or imply its endorsemeat, recommendation, or favoring by the United States Government or the University of Colifornil. The views and opinions of authors expressed herein do not necessarily state or reflect those of the United States Government or the University of California, and shall not be used for advertising or product endorsement purposes. 


\section{LOCALIZED DRYOUT: AN APPROACH FOR MANAGING THE THERMAL- HYDROLOGICAL EFFECTS OF DECAY HEAT AT YUCCA MOUNTAIN}

THOMAS A. BUSCHECK*, JOHN J. NTTAO*, AND LAWRENCE D. RAMSPOTT**

*Earth Sciences Division, LLNL, *TRW (all at Lawrence Livermore National Laboratory, L-206, P.O. Box 808, Livermore, CA 94551)

\section{ABSTRACT}

For a nuclear waste repository in the unsaturated zone at Yucca Mountain, there are two thermal loading approaches to using decay heat constructively-that is, to substantially reduce relative humidity and liquid flow near waste packages for a considerable time, and thereby limit waste package degradation and radionuclide dissolution and release. "Extended dryout" achieves these effects with a thermal load high enough to generate large-scale (coalesced) rock dryout. "Localized dryout" (which uses wide drift spacing and a thermal load too low for coalesced dryout) achieves them by maintaining a large temperature difference between the waste package and drift wall; this is done with close waste package spacing (generating a high line-heat load) and/or low-thermal-conductivity backfill in the drift. Backfill can greatly reduce relative humidity on the waste package in both the localized and extended dryout approaches. Besides using decay heat constructively, localized dryout reduces the possibility that far-field temperature rise and condensate buildup above the drifts might adversely affect waste isolation.

\section{INTRODUCTION}

The U.S. Department of Energy is investigating the feasibility of disposing of radioactive wastes, including spent nuclear fuel (SNF) from electrical utilities and wastes stored at federal facilities, in the unsaturated zone (UZ) at Yucca Mountain, Nevada. To be feasible, the waste isolation system must limit the release and transport of radionuclides in those wastes to the accessible environment. Waste isolation is affected by three key factors: (1) the ambient relative humidity in the $\mathrm{UZ}$ is high $(R H \approx 98-99 \%)$ and is therefore corrosive for most candidate waste package (WP) materials; (2) ambient fracture flow is highly variable in time and space; and (3) radioactive decay heat significantly affects fluid flow for any practical areal mass loading (AML, expressed in metric tons of uranium per acre, MTU/acre). Two thermal loading strategies have been proposed to manage the thermal-hydrological (T-H) effects of decay heat:

Minimally heated (MH) repository: Select an AML and a thermal load distribution that limit (1) heat-driven vapor and condensate flow and (2) far-field temperature rise. The MH strategy relies on performance attributes other than decay heat (such as high-performance WP materials and capillary/diffusion barriers) to counter the effects of high $\mathrm{RH}$ and fast fracture flow.

Constructively heated (CH) repository: Select an AML and a thermal load distribution that use decay heat to substantially reduce $R H$ and fracture flow near WPs. The CH strategy relies on demonstrating that heat, vapor, and liquid flow (including heterogeneous fracture flow) near WPs are dominated by heat conduction and are therefore predictable.

This paper addresses only the $\mathrm{CH}$ strategy. We have identified two $\mathrm{CH}$ approaches:

Extended dryout (ED) approach: Use a high AML (>60 MTU/acre) to drive a large fraction of the pore water (in the rock) from the repository as a whole. The high areal thermal power density associated with such an AML creates a thick superheated dryout zone (coalesced between emplacement drifts) and maintains above-boiling temperatures and low $R H$ in the repository rock (and on WPs) for thousands of years [1-3].

Localized dryout (LD) approach: Maintain a temperature difference between the WP and drift wall large enough to reduce $R H$ on the WP. This is done with close axial WP spacing (generating a high line-heat load) and/or the use of low-thermal-conductivity backfill in the drift. Wide drift spacings and low to intermediate AMLs ( $<50-60 \mathrm{MTU} /$ acre) are used to (1) prevent the boiling zones from coalescing between drifts (thereby limiting condensate buildup above the drifts) and (2) limit far-field temperature rise (as in the MH strategy). This is the first paper describing the LD approach.

Two major decay-heat-driven T-H issues may affect waste isolation for the ED approach (the first must be addressed for all AMLs; the second is unique to the ED approach):

Coupled T-H-M-C effects: Thermal-hydrological-mechanical-chemical effects in the near and far field must be addressed regardless of AML; however, their impact on waste 
isolation may depend on AML. The effects of particular concern are (a) alteration of the vitric nonwelded Paintbrush tuff (PTn) unit, which may reduce its ability to attenuate (in time and space) net infiltration to the repository and (b) alteration of the basal vitrophyre (TSw3) unit, which may influence whether water perches in (or immediately above) that unit and may reduce the mechanical stability of the drifts in the repository.

Condensate buildup above the boiling zone: Condensate and infiltration flux may be held up by the thick superheated dryout zone created by a high-AML repository.

The LD approach (like the MH strategy) tends to limit far-field T-H-M-C effects and allows condensate to drain through the repository; neither of these results is as readily achieved with the ED approach. The LD approach can be implemented by a wide range of thermal design options, ranging from those that never cause above-boiling temperatures to those in which the WP temperature is above boiling for thousands of years.

A major concern for radionuclide containment is how water contacts a WP, thereby affecting its integrity and (if containment is breached) affecting radionuclide dissolution and eventual transport to the water table. The degradational mechanisms of greatest concern for WP integrity, such as stress and pitting corrosion or microbial attack, require the presence of liquid water. The rates for many of these mechanisms increase, in general, with temperature and relative humidity.

The two primary modes of water contact on the WP are (1) advective liquid-phase flow and (2) condensation of water vapor that forms a liquid film on the WP. The critical factor for the second mode is the relative humidity $R H$ on the WP. Relative humidity is given by

$$
R H=\frac{P_{\mathrm{v}}}{P_{\mathrm{sat}}(T)},
$$

where $P_{\mathrm{v}}$ is the local vapor pressure and $P_{\text {sat }}$ is the local saturated vapor pressure. If $100 \%$ of the gas phase is water vapor, as is the case for boiling conditions, then $P_{\mathrm{v}}=P_{\mathrm{g}}$, where $P_{\mathrm{g}}$ is the total gas-phase pressure. For example, if $P_{\mathrm{v}}=P_{\mathrm{g}}=1 \mathrm{~atm}$ and $T=T_{\mathrm{wp}}=225^{\circ} \mathrm{C}$, then (from steam tables) $P_{\text {sat }}=25.48 \mathrm{~atm}$ and $R H_{\mathrm{wp}}=3.9 \%$. The assumption that $P_{\mathrm{v}}=1 \mathrm{~atm}$ is reasonable if there is enough fracture connectivity and conductivity so that bulk permeability $k_{\mathrm{b}}>1$ millidarcy. If there were no fractures in the repository rock, then we would have $k_{\mathrm{b}} \ll 1$ millidarcy, and $P_{\mathrm{v}}$ would be much higher than $1 \mathrm{~atm}$; this would increase $R H$ by a corresponding factor. An important question, resolvable with in situ thermal tests [4], is whether fracture conductivity and connectivity are sufficient to prevent substantial pressurization of the gas phase near WPs.

Regardless of whether mobile liquid water is present, ambient $R H$ at the repository horizon is high ( $98-99 \%$ ). If $R H$ were reduced enough, WP corrosion rates would be minimal [5]. Moreover, even for breached WPs, waste-form dissolution (and radionuclide release) would be minimal if no mobile liquid water were present. There are two ways to reduce $R H$ on the WP:

1. Drive a large fraction of the ambient pore water (in the rock) away from the drifts. (This reduces $R H$ in the rock; $R H$ on the WP can be no greater than $R H$ in the rock.)

2. Maintain a large temperature difference between the (hotter) WP and the (cooler) drift wall. (This makes $R H$ on the WP lower than $R H$ in the rock at the drift wall.) The primary means of driving pore water away from the drifts are drift ventilation and decay-heat-driven drying; the latter of which requires above-boiling rock temperatures.

Even if decay heat does not reduce $R H$ in the rock, it is still possible to substantially reduce $R H$ on the WP itself for a considerable time. A reduction in $R H$ between the drift wall and WP $\left(\Delta R H_{\text {drift }}\right)$ arises from the temperature difference $\Delta T_{\text {drift }}$ between these locations. This effect (the "drift- $\Delta R H$ effect") occurs in addition to any reduction in $R H$ resulting from rock dryout $\left(\Delta R H_{\text {rock }}\right.$ ). Assuming uniform $P_{\mathrm{v}}$ in the drift, $R H$ on the WP is given by

$$
R H_{\mathrm{wp}}=R H_{\mathrm{dw}} \frac{P_{\mathrm{sat}}\left(T_{\mathrm{dw}}\right)}{P_{\mathrm{sat}}\left(T_{\mathrm{wp}}\right)},
$$

where $R H_{\mathrm{dw}}$ is $R H$ in the rock at the drift wall, and $T_{\mathrm{dw}}$ and $T_{\mathrm{wp}}$ are the drift wall and WP temperatures. For example, if $T_{\mathrm{dw}}=80^{\circ} \mathrm{C}, T_{\mathrm{wp}}=100^{\circ} \mathrm{C}$, and $R H_{\mathrm{dw}}=98.4 \%$ (ambient $\left.R H\right)$, then we have $R H_{\mathrm{wp}}=46 \%$.

A persistent $\Delta T_{\text {drift }}$ arises because the rows of WPs act like line-heat loads that impose a temperature increase on top of the temperature rise $\Delta T_{\text {rock }}$ in the repository rock; $\Delta T_{\text {rock }}$ depends 
primarily on AML and the thermal conductivity $K_{\mathrm{th}}$ of the mountain [1-3]. Because $\Delta T_{\text {drift }}$ depends only on lineal mass loading (LML, expressed in $\mathrm{MTU} / \mathrm{m}$ of drift) and the thermal properties of the drift, $\Delta T_{\text {drift }}$ is increased by high $L M L$ and/or the use of low $-K_{\text {th }}$ granular backfill in the drift. Proving that heat flow in the backfill is dominated by conduction establishes that $\Delta T_{\text {drift }}$ is predictable. Note that Eq. (2) is applicable when $P_{\mathrm{v}}$ on the WP is in equilibrium with $P_{\mathrm{v}}$ in the rock at the drift wall. Nonuniform (or episodic) rewetting of the drift by heterogeneous fracture flow may locally (or temporarily) cause $R H$ to be higher than predicted by Eq. 2 .

Whether liquid-phase flow reaches a WP is also a concern. An important issue for WP integrity involves the scenario of liquid water reaching and evaporating on a WP, leaving a salt buildup on the WP. The $R H$ necessary for condensation of an aqueous surface film on the WP will depend on the composition and relative abundances of hygroscopic salts on the WP. The critical relative humidity $R H_{\text {crit }}$ for significant aqueous corrosion is sensitive to this effect [6]; the absence of salts on the WP could result in $R H_{\text {crit }}>90 \%$. Keeping liquid-phase flow away from the WP would limit the precipitation of salts on the WP and thereby keep $R H_{\text {crit }}$ high, which would greatly increase WP lifetimes and the duration of radionuclide containment. A suitable backfill might significantly reduce the likelihood of salt precipitation on the WP.

\section{NUMERICAL MODELS AND ASSUMPTIONS}

Model calculations were carried out using the V-TOUGH and NUFT codes [7-9], which simulate the three-dimensional coupled transport of water, vapor, air, and heat in fractured porous media. Our models include all major hydrostratigraphic units in the UZ, which are assumed to be horizontal and of uniform thickness; the initial and boundary conditions were the same as those used in past studies [1-3]. We assumed $k_{\mathrm{b}}=280$ millidarcy, and we used an initial vertical liquid saturation profile based on a zero net infiltration flux of meteoric water; however, a wide range of other conditions have also been considered [2]. The atmospheric $R H$ is assumed to be $100 \%$, so the model allows no loss of moisture by vapor diffusion to the atmosphere. Because actual (desert) $R H$ is much lower than $100 \%$, the model underrepresents this loss. This neglected loss may be large for high AMLs, which can steepen the temperature gradient near the ground surface by a factor of 50 relative to ambient conditions. The effect of this assumption is offset (to some degree) by the assumption of zero net infiltration flux.

Drift-scale T-H behavior is represented by a two-dimensional model that incorporates the geometric details of the WPs and emplacement drifts in a cross section transverse to the drift axes. Because this model effectively assumes an infinite repository area, it is applicable to the region not affected by cooling at the repository edge. Calculations for the repository edge were carried out with a two-dimensional hybrid model that imbeds a drift-scale model in a mountain-scale model. To determine the boundaries between the LD and ED domains (with respect to thermal design parameters), we considered AMLs of 6 to $120 \mathrm{MTU} /$ acre, drift spacings $L_{\mathrm{d}}$ of 25 to $400 \mathrm{~m}$, and LMLs of 0.2 to $1.25 \mathrm{MTU} / \mathrm{m}$. An oldest-fuel-first receipt scenario with 26-yr-old SNF and a mix of 40 BWR WPs and 21 PWR WPs was assumed for the decayheat-generation curve. We also considered the effect of aging the SNF to ages of $40,60,100$, and $200 \mathrm{yr}$. Cases in which the drift is backfilled at $100 \mathrm{yr}$ were compared with those with no backfill.

\section{DISCUSSION OF MODEL RESULTS}

A primary concern for the ED approach is whether condensate buildup above the boiling zone has a deleterious effect on waste isolation. For both the ED and LD approaches, this buildup is affected by several key factors: (1) whether (and by how much) the decay-heatsteepened temperature gradient near the ground surface increases the exfiltration flux to the atmosphere (moisture loss by advective and diffusive vapor transport), (2) the infiltration flux, (3) the rate at which pore water in the rock is vaporized and transported above the boiling zone (where it condenses), and (4) how effectively liquid-phase drainage around the boiling zone (or zones) mitigates condensate buildup above the boiling zone(s). Factors 1,through 3 determine the liquid-phase flux that reaches the top of boiling zone(s); factor 4 influences how much of that flux drains around (and below) the boiling zone(s). The ED approach (and, to a lesser extent, the LD approach) may increase exfiltration flux (factor 1). The LD approach will limit condensate flux (factor 3 ) and prevent the boiling zones from coalescing between drifts, thereby allowing condensate to drain between the drifts (factor 4). 
Figure 1a,c gives the maximum vertical distance $\Delta Z_{\max }$ of the upper boiling front from the repository horizon as a function of AML for various SNF ages. The boiling zones are initially cylindrical (centered at the drift axis) with a radius equal to $\Delta Z_{\text {maxi }}$ after they coalesce (in the ED approach), the coalesced zone is tabular (centered at the repository horizon) with a vertical thickness of $2 \Delta Z_{\max }$. Examination of the temperature fields for a wide range of cases shows that uncoalesced (cylindrical) boiling (that is, localized dryout) persists as long as $\Delta Z_{\max }<L_{d} / 2$; coalesced (tabular) boiling (that is, extended dryout) occurs for $\Delta Z_{\max }>L_{\mathrm{d}} / 2$. This observation permits us to distinguish between the LD and ED domains in Fig. 1a,c. Figure 2 gives the

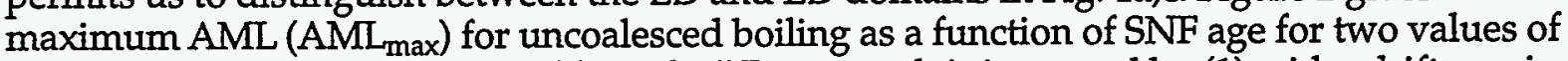
LML. The range of AMLs amenable to the LD approach is increased by (1) wider drift spacings (higher LMLs), (2) SNF aging, and (3) drift ventilation.

Another benefit of wide drift spacing (high LMLs) is that peak WP (and drift-wall) temperature $T_{\text {peak }}$ is insensitive to AML (Fig. 1b,d). This means that WPs could be emplaced in every other drift, and the decision of whether to fill the remaining drifts deferred until enough information about T-H behavior was available from in situ thermal tests [4] and repository performance monitoring. Because $T_{\text {peak }}$ in the near field is insensitive to AML for high LMLs, similar near-field environment (NFE) design assumptions concerning $T_{\text {peak }}$ will be applicable to a wide range of thermal loading (and WP emplacement) options. These results also indicate that $T_{\text {peak }}$ in the near field is insensitive to proximity to the repository edge; NFE design assumptions concerning $T_{\text {peak }}$ will therefore be similar for the entire repository area. Another advantage for high LMLs is that the total length of emplacement drifts depends on LML and is independent of AML (and repository area). Some of the potential cost savings in constructing a high-AML repository could also be realized in a low-AML repository that uses the same LML.

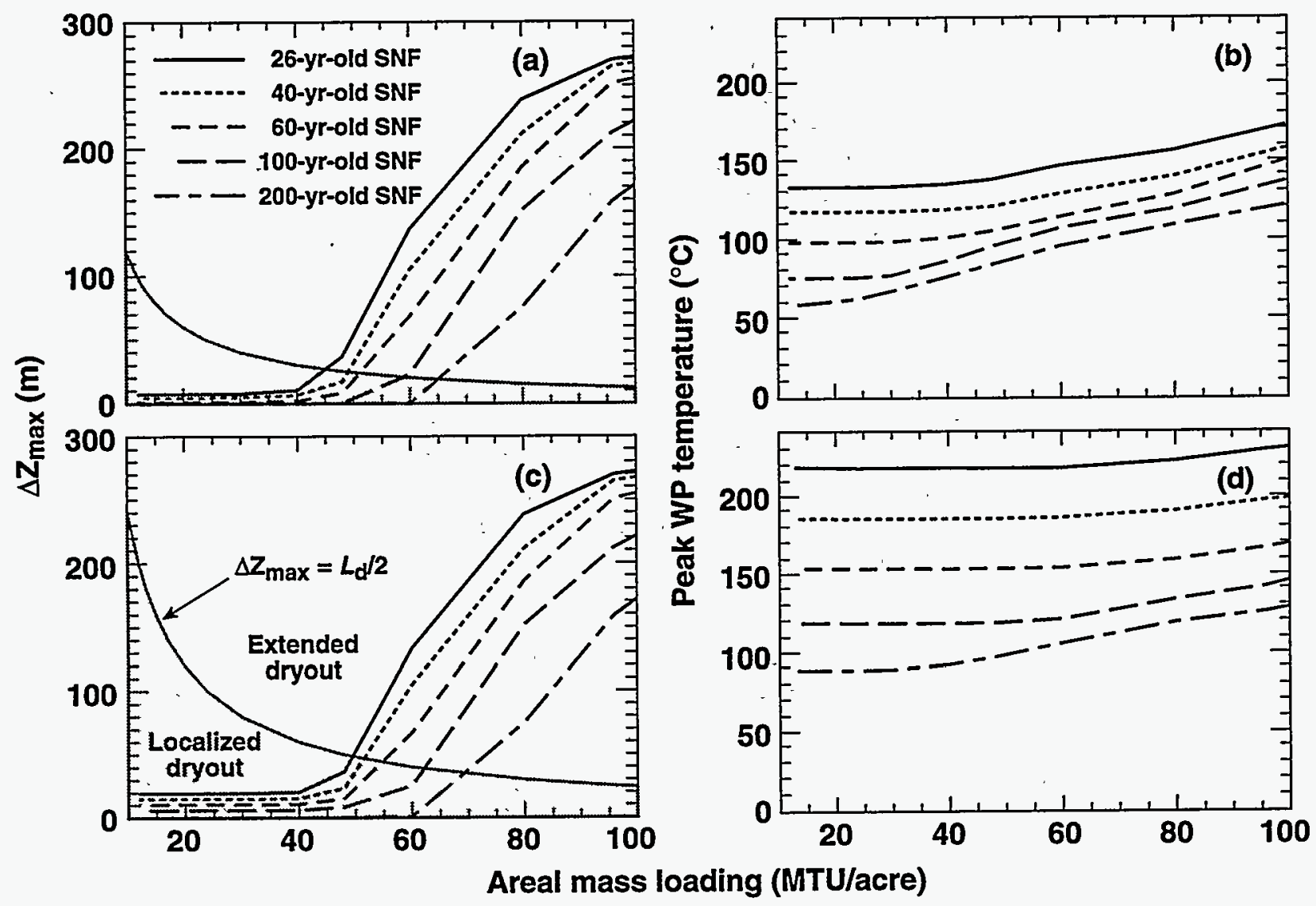

Figure 1. (a) Maximum vertical distance $\Delta \mathrm{Z}_{\max }$ of the upper boiling front from the repository horizon and (b) peak temperature on the WP as a function of AML for various SNF ages, $\mathrm{LML}=0.63 \mathrm{MTU} / \mathrm{m}$, no backfill, bulk permeability $k_{\mathrm{b}}=280$ millidarcy, and vapor diffusion tortuosity factor $\tau_{\mathrm{eff}}=0.2$. Curves are also shown (c,d) for $L M L=1.25 \mathrm{MTU} / \mathrm{m}$ and WP spacing $=6 \mathrm{~m}$. In (a) and (c), the curve separating the ED and $L D$ domains corresponds to $\Delta Z_{\max }$ equal to one-half the drift spacing $L_{\mathrm{d}} / 2$. 
Still another benefit of wide drift spacing is that the drift- $\triangle R H$ effect is maximized for any given AML. Figure $3 \mathrm{~b}$ shows this effect for a 40-MTU/acre example of the LD approach. Higher LMLs increase $\Delta T_{\text {drift }}$ and thereby increase $\Delta R H_{\text {drift. }}$ This increase in $\Delta R H_{\text {drift }}$ occurs even though far-field temperatures are nearly identical for these cases (not shown in Fig. 3) and near-field temperatures are similar after about $2000 \mathrm{yr}$ (Fig. 3a). Thus, it is possible with the LD approach to substantially reduce $R H$ on the WP while limiting far-field temperature rise.

We analyzed the effect of a granular backfill on $\Delta R H_{\text {drift }}$ for the LD approach (Fig. 4). We assumed that the intergranular porosity of a crushed PTn tuff backfill can be treated like fractures in the equivalent continuum model [2] with $k_{\mathrm{b}}=40$ darcy. The hydrological properties of the granular porosity are assumed to be that of the intact rock matrix, and the drying curves measured by Peters et al. [10] are assumed to be applicable to matrix imbibition; both assumptions probably overrepresent the tendency of water to be wicked back to the WP and are therefore conservative. For most of the calculations, the dry and wet values of $K_{\text {th }}$ were assumed to be one-half the intact $P T n$ values $\left(0.305\right.$ and $0.425 \mathrm{~W} \mathrm{~m}^{-1}{ }^{\circ} \mathrm{C}^{-1}$, respectively).

After backfill is emplaced at $t=100 \mathrm{yr}, T_{\mathrm{wp}}$ increases abruptly from 100 to $210^{\circ} \mathrm{C}$ (Fig. 4a), decreasing $R H_{\text {wp }}$ from 62 to $2.7 \%$ (Fig. 4b). Because of the low AML (24 MTU/acre), negligible $R H$ reduction results from rock dryout ( $\Delta R H_{\text {rock }}$, Table I). Because of the larger $\Delta T_{\text {drift }}$ backfill results in a much larger $\Delta R H_{\text {drift }}$ than when backfill is not used. At $t=10,000 \mathrm{yr}, R H_{\mathrm{wp}}=71$ and $93 \%$ for backfill and no backfill, respectively (Fig. $4 \mathrm{~b}$ ). An important benefit of backfill is that $R H_{\mathrm{wp}}$ may remain low until $T_{\mathrm{wp}}$ is quite low. With backfill (at $t=21,000 \mathrm{yr}$ ), $R H_{\mathrm{wp}}=81 \%$ and $T_{\mathrm{wp}}=34^{\circ} \mathrm{C}$; with no backfill (at $t=715 \mathrm{yr}$ ), $R H_{\mathrm{wp}}=81 \%$ and $T_{\mathrm{wp}}=77^{\circ} \mathrm{C}$; backfill can therefore substantially reduce the $T_{\mathrm{wp}}$ associated with a given $R H_{\mathrm{wp}}$.

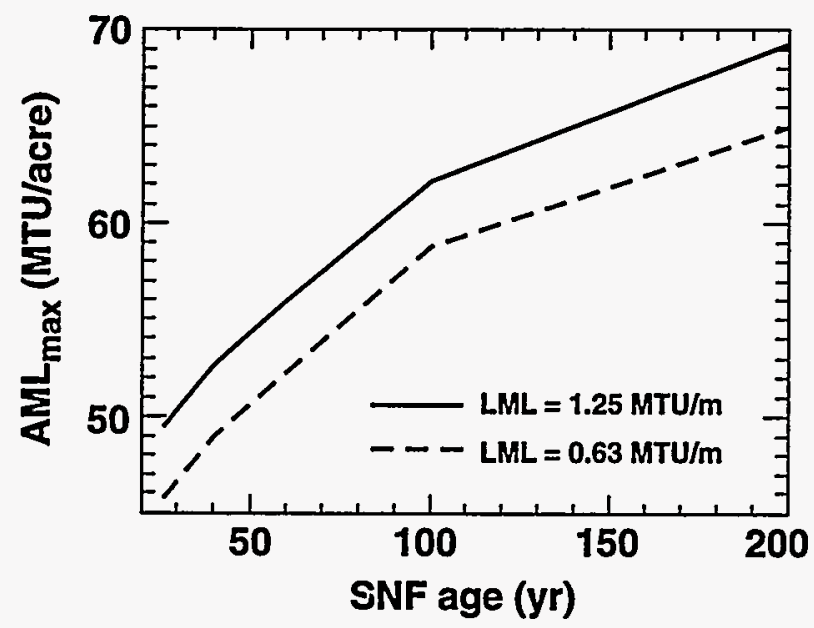

Figure 2. The maximum $A M L(A M L \max$ ) for uncoalesced boiling as a function of SNF age. Combinations of AML and SNF age lying below a given curve result in uncoalesced (cylindrical) boiling zones (that is, localized dryout); combinations lying above a given curve result in coalesced (tabular) boiling zones (that is, extended dryout). Higher LMLs (and larger $L_{\mathrm{d}}$ ) and older SNF increase the range of AMLs amenable to the LD approach. The effect of emplacing older SNF may also be achieved (with younger SNF) by ventilating the emplacement drifts to remove water vapor (and its associated latent heat) from the drifts and from the repository rock.

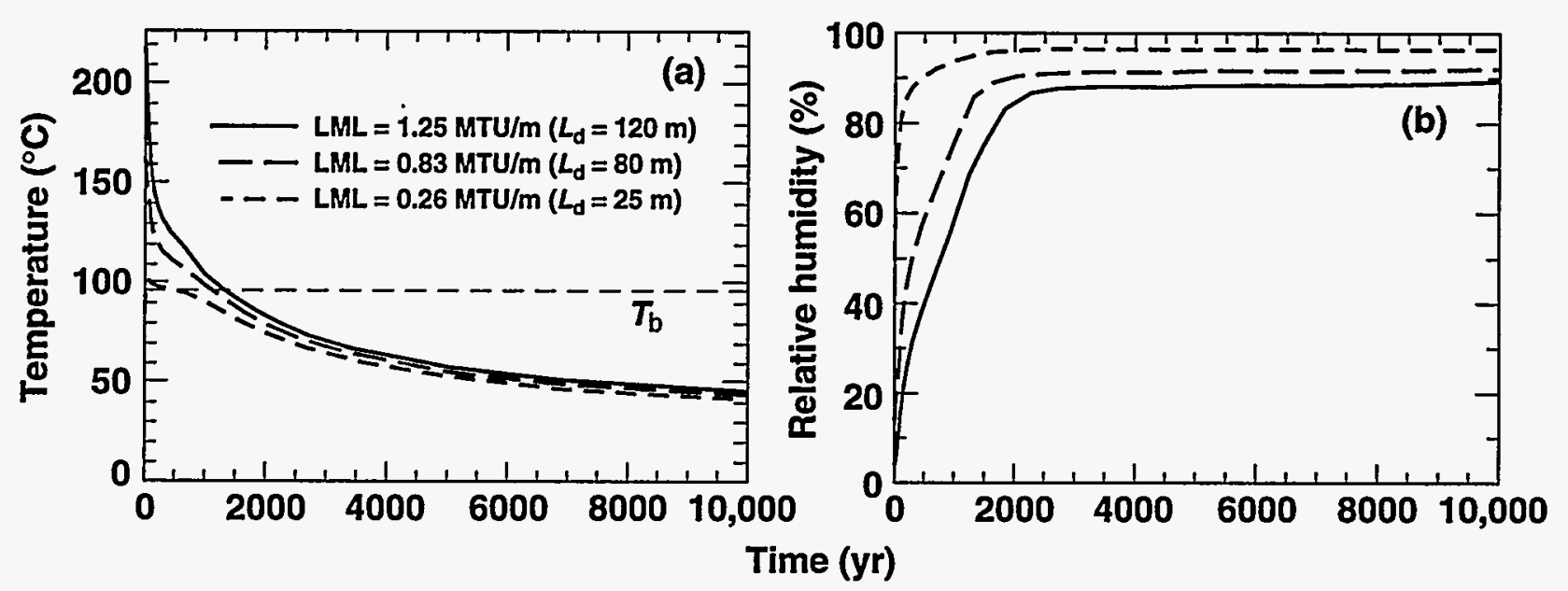

Figure 3. (a) Temperature and (b) relative humidity on the WP surface for AML $=40 \mathrm{MTU} / \mathrm{acre}$, 26-yr-old SNF, no backfill, bulk permeability $k_{\mathrm{b}}=280$ millidarcy, and vapor diffusion tortuosity factor $\tau_{\text {eff }}=0.2$ for three values of LML. 
We analyzed other backfill types, including 10-darcy sand. On the basis of this analysis, we identified five potentially beneficial performance attributes for backfill:

1. Persistent large temperature difference $\left(\Delta T_{\text {drift }}\right)$ between the WP and the drift wall that substantially reduces $R H$ on the WP. The reduction in $R F I$ is most effective if $\Delta T_{\text {drift }}$ is predictable and if the backfill does not strongly wick moisture back to the WP.

2. Capillary barrier that attenuates focused liquid flux (including fracture flow).

3. High heat capacity (relative to air) and high $\Delta T_{\text {drift }}$ that evaporates the liquid flux and equilibrates $P_{\mathrm{v}}$ in the drift with that in the adjacent repository rock.

4. Limited liquid contact on the WP, which prevents evaporative salt buildup.

5. Limited moisture contact on the WP, which reduces radionuclide dissolution and release, and limited moisture content in the backfill, which reduces transport in the drift.

We also analyzed the effect of backfill on $\Delta R H_{\text {drift }}$ for the ED approach (Fig. 4). After backfill is emplaced at $t=100 \mathrm{yr}, T_{\mathrm{wp}}$ increases abruptly from 148 to $266^{\circ} \mathrm{C}$ (Fig. 5a), reducing

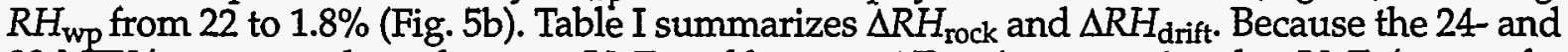
80-MTU/acre cases share the same LML and because $\Delta T_{\text {drift }}$ is proportional to LML (except for early time, when thermal radiation in the drift is also sensitive to absolute temperature), $\Delta T_{\text {drift }}$ is the same in both cases. The ratio $R H_{\mathrm{wp}} / R H_{\mathrm{dw}}$ is insensitive to AML for $t>2000 \mathrm{yr}$. [From Eq. 2, we have $R H_{\mathrm{wp}} / R H_{\mathrm{dw}}=P_{\text {sat }}\left(T_{\mathrm{dw}}\right) / P_{\mathrm{sat}}\left(T_{\mathrm{wp}}\right)$.] Later, the difference in absolute temperature between the two cases decreases, so that $P_{\text {sat }}\left(T_{\mathrm{dw}}\right) / P_{\text {sat }}\left(T_{\mathrm{wp}}\right)$ depends primarily on $\Delta T_{\text {drift: }}$ therefore, $R H_{\mathrm{wp}} / R H_{\mathrm{dw}}$ depends primarily on LML and the thermal properties of the backfill and is insensitive to AML, drift spacing, and location in the repository (i.e., proximity to the edge).

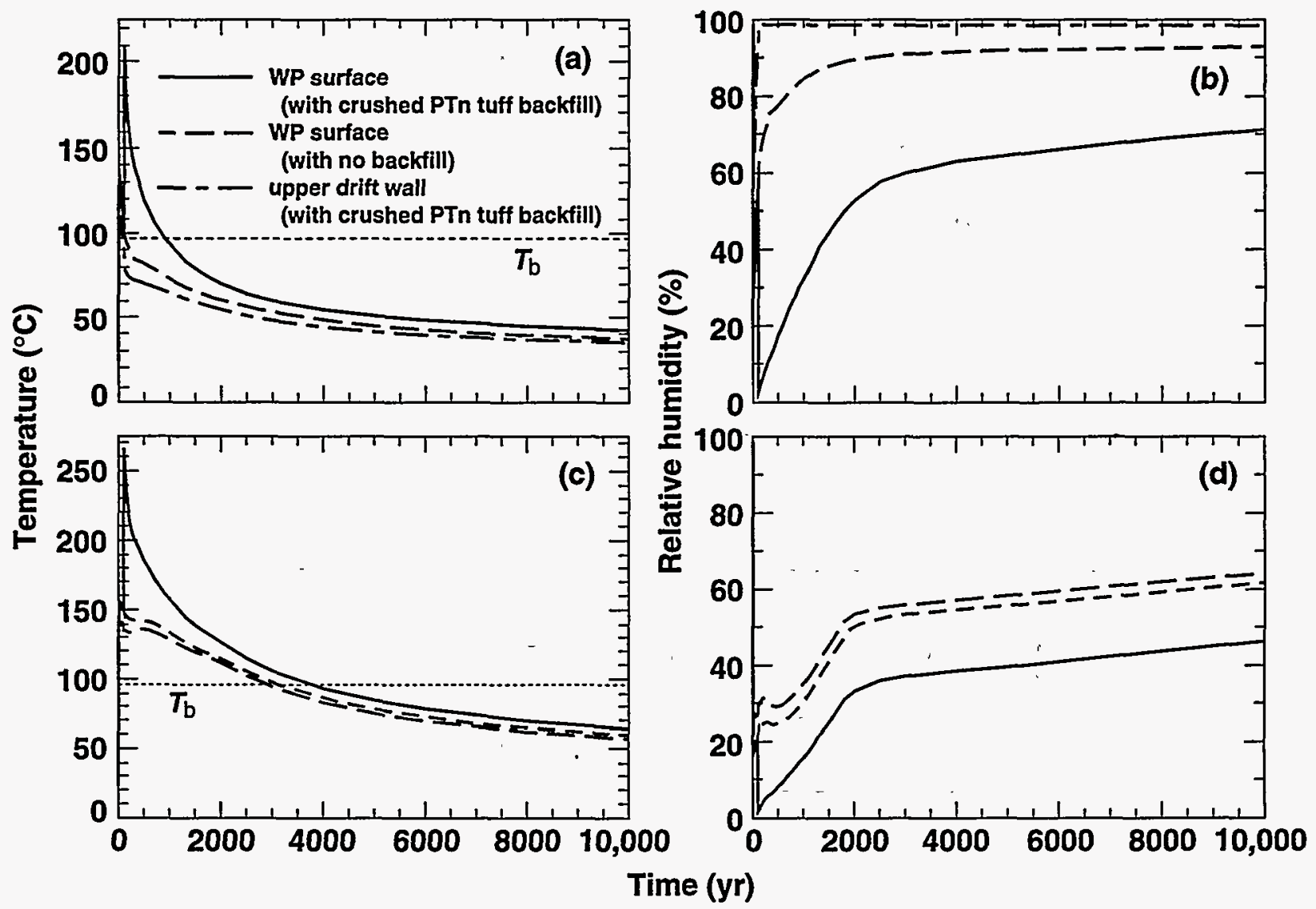

Figure 4. (a) Temperature and (b) relative humidity on the WP surface and in the rock at the upper drift wall for $\mathrm{AML}=24 \mathrm{MTU} / \mathrm{acre}$, 26-yr-old SNF, $\mathrm{LML}=0.63 \mathrm{MTU} / \mathrm{m}, L_{\mathrm{d}}=100 \mathrm{~m}$, bulk permeability $k_{\mathrm{b}}=280$ millidarcy, and vapor diffusion tortuosity factor $\tau_{\mathrm{eff}}=0.2$. (c, d) Same as $(\mathrm{a}, \mathrm{b})$ except for $\mathrm{AML}=80 \mathrm{MTU} / \mathrm{acre}$ and $L_{\mathrm{d}}=30 \mathrm{~m}$. Curves are shown for backfill emplaced at $t=100 \mathrm{yr}$ and no backfill. Temperature and relative humidity at the upper drift wall with no backfill is very similar to that shown for the case with backfill. . 
Table I. Relative humidity reduction contributed by repository rock dryout ( $\Delta R H_{\text {rock }}$ ) and by the drift- $\Delta R H$ effect $\left(\Delta R H_{\text {drift }}\right)$ for $\mathrm{LML}=0.63 \mathrm{MTU} / \mathrm{m}$ and crushed PTn tuff backfill

\begin{tabular}{|c|c|c|c|c|c|c|c|c|c|}
\hline \multirow[t]{2}{*}{ AML } & & \multicolumn{8}{|c|}{ time(yr) } \\
\hline & & 60 & 100 & 2000 & 10,000 & 20,000 & 40,000 & 60,000 & 100,000 \\
\hline \multirow{8}{*}{$24 \mathrm{MTU} / \mathrm{acre}$} & $R H_{\mathrm{wp}}(\%)$ & 46 & 2.7 & 53 & 71 & 80 & 89 & 92 & 94 \\
\hline & $\left.T_{\mathrm{wp}}{ }^{\circ} \mathrm{C} \mathrm{C}\right)$ & 118 & 210 & 69 & 42 & 34 & 29 & 27 & 26 \\
\hline & $R H_{\mathrm{dw}}(\%)$ & 82 & 96 & 98.6 & 98.5 & 98.4 & 98.4 & 98.4 & 98.4 \\
\hline & $R H_{\mathrm{wp}} / R H_{\mathrm{dw}}$ & 0.56 & 0.03 & 0.54 & 0.72 & 0.81 & 0.90 & 0.94 & 0.96 \\
\hline & $\Delta T_{\text {drift }}\left({ }^{\circ} \mathrm{C}\right)$ & 17 & 131 & 15 & 7.1 & 4.3 & 2.1 & 1.4 & 0.9 \\
\hline & $\Delta R H_{\text {rock }}(\%)$ & 16 & 2 & 0 & 0 & 0 & 0 & 0 & 0 \\
\hline & $\Delta R H_{\text {drift }}(\%)$ & 36 & 94 & 46 & 27 & 18 & 9 & 6 & 4 \\
\hline & $\Delta R H_{\text {total }}(\%)$ & 52 & 96 & 46 & 27 & 18 & 9 & 6 & 4 \\
\hline \multirow{8}{*}{80 MTU/acre } & $R H_{\mathrm{wp}}(\%)$ & 19 & 1.8 & 33 & 46 & 59 & 78 & 90 & 94 \\
\hline & $\left.T_{\text {wp }}{ }^{(\circ} \mathrm{C}\right)$ & 153 & 266 & 127 & 64 & 47 & 35 & 31 & 28 \\
\hline & $R H_{d w}(\%)$ & 27 & 30 & 54 & 64 & 73 & 87 & 96 & $\overline{98}$ \\
\hline & $R H_{\mathrm{wp}} / R H_{\mathrm{dw}}$ & 0.70 & 0.06 & 0.61 & 0.72 & 0.81 & 0.90 & 0.94 & 0.96 \\
\hline & $\Delta T_{\text {drift }}\left({ }^{\circ} \mathrm{C}\right)$ & 12 & 131 & 15 & 7.1 & 4.3 & 2.1 & 1.4 & 0.9 \\
\hline & $\Delta R H_{\text {rock }}(\%)$ & 71 & 69 & 44 & 34 & 25 & 11 & 2 & 0 \\
\hline & $\Delta R H_{\text {drift }}(\%)$ & 8 & 28 & 21 & 18 & 14 & 9 & 6 & 4 \\
\hline & $\Delta R H_{\text {total }}(\%)$ & 79 & 97 & 65 & 52 & 39 & 20 & 8 & 4 \\
\hline
\end{tabular}

For the LD approach, $\Delta R H_{\text {drift }}$ is always the major contributor to $R H$ reduction on the WP (Table I) everywhere in the repository (including the edge). For the ED approach, $\Delta R H_{\text {rock }}$ can play a major role in $R H$ reduction during the first 20,000 to $40,000 \mathrm{yr}$ in the central half of the repository and during the first $5000 \mathrm{yr}$ at the repository edge. For the 80-MTU/acre repository, $\Delta R H_{\text {drift }}$ becomes the major contributor to $R H$ reduction for $t>60,000 \mathrm{yr}$ in the central half of the repository and for $t>5000 \mathrm{yr}$ at the edge. At late time, $R H$ reduction depends primarily on the thermal and hydrological properties of the backfill (notably $K_{\text {th }}$ and rewetting diffusivity) and is insensitive to AML, drift spacing, and location in the repository. At late time, $R H$ reduction for a high-AML repository is similar to that of a low-AML repository having the same LML.

\section{CONCLUSIONS}

There are two thermal loading approaches to using decay heat constructively in a repository located in the unsaturated zone at Yucca Mountain. In both approaches, decay heat reduces relative humidity and liquid flux near waste packages (WPs) for a considerable time, and thereby limits WP degradation and radionuclide dissolution and release. The extended dryout (ED) approach achieves these effects by using an areal mass loading (AML >60 MTU/acre) high enough to develop a thick superheated dryout zone (coalesced between emplacement drifts), and thereby drive pore water away from the drifts. The localized dryout (LD) approach achieves these effects by maintaining a large temperature difference between the WP and the drift wall. The LD approach uses close axial WP spacing (generating a high line-heat load) in widely spaced drifts and an AML ( $<50-60$ MTU/acre) that (1) is low enough that the boiling zones do not coalesce between drifts, thereby limiting condensate buildup above the drifts, and (2) limits far-field temperature rise. Higher lineal mass loadings (LML), wider drift spacings, and older spent nuclear fuel (SNF) increase the range of AMLs amenable to the LD approach. Both the ED and LD approaches rely on demonstrating that heat, vapor, and liquid flow near WPs are dominated by heat conduction and are therefore predictable.

Relative humidity on the WP can be reduced as a result of two effects: (1) repository rock dryout and (2) the temperature difference between the WP and drift wall ("drift- $\Delta R H$ effect"). For the ED approach, the first effect may be significant for tens of thousands of years. For both 
the ED and LD approaches, the second effect is enhanced with high a LML (close axial WP spacing) and/or the use of a suitable low-thermal-conductivity granular backfill in the drift. Backfill is most effective if the vapor pressure on the WP is in equilibrium with that in the adjacent rock. The drift- $\triangle R H$ effect depends primarily on LML and the thermal properties of the drift (backfill) and is insensitive to AML, drift spacing, and location in the repository (i.e., proximity to the edge). For both the ED and LD approaches, the drift- $\Delta R H$ effect can be large for tens of thousands of years, keeping the relative humidity on the WP low until the WP temperature is quite low. Backfill may also keep liquid water from reaching and evaporating on the WP, and thereby limit salt buildup on the WP; this could help maintain a high critical relative humidity for aqueous corrosion of the WP and could thereby greatly increase WP lifetimes and the duration of radionuclide containment.

\section{ACKNOWLEDGEMENTS}

We acknowledge the review of Ken Jackson, the editorial assistance of Peter Murphy, and the graphical support of Rick Wooten. This work was supported by the Yucca Mountain Site Characterization Project. Work performed under the auspices of the U.S. Department of Energy by Lawrence Livermore National Laboratory under Contract W-7405-Eng-48.

\section{REFERENCES}

1. -Buscheck, T.A., and J.J. Nitao, "Repository-Heat-Driven Hydrothermal Flow at Yucca Mountain, Part I: Modeling and Analysis," Nuclear Technology, Vol. 104, No. 3, pp. 418-448 (1993). 2. Buscheck, T.A., and J.J. Nitao, "The Impact of Buoyant Gas-Phase Flow and Heterogeneity on Thermo-Hydrological Behavior at.Yucca Mountain," American Nuclear Society, La Grange Park, IL, Proceedings Fifth International High-Level Radioactive Waste Management Conference, Las Vegas, NV, May 1994. Also UCRL-JC-115351, Lawrence Livermore National Laboratory, Livermore, CA (1994).

3. Buscheck, T.A. and J.J. Nitao, "The Importance of Thermal Loading Conditions to Waste Package Performance at Yucca Mountain," Materials Research Society, Pittsburgh, PA, Proceedings Materials Research Society XVIII International Symposium on the Scientific Basis for Nuclear Waste Management, Oct. 23-27, 1994. Also UCRL-JC-116429, Lawrence Livermore National Laboratory, Livermore, CA (1994).

4. Buscheck, T.A., and J.J. Nitao, "Thermal-Hydrological Analysis of Large-Scale Thermal Tests in the Exploratory Studies Facility at Yucca Mountain," UCRL-ID-121791, Lawrence Livermore National Laboratory, Livermore, CA (1995).

5. Stahl, D., J.K. McCoy, and R.D. McCright, "Impact of Thermal Loading on Waste Package Material Performance," Material Research Society, Pittsburgh, PA, Proceedings Material Research Society XVIII Symposium on the Scientific Basis for Nuclear Waste Management, Oct. $23-27$ (1994). 6. Jones, D.A., Principles and Prevention of Corrosion, Macmillan Publishing Company, New York (1992).

7. Nitao, J.J., "V-TOUGH - An Enhanced Version of the TOUGH Code for the Thermal and Hydrologic Simulation of Large-Scale Problems in Nuclear Waste Isolation," UCID-21954,

Lawrence Livermore National Laboratory, Livermore, CA (1989).

8. Pruess, K., "TOUGH User's Guide," NUREG/CR-4645, Nuclear Regulatory Commission (1987).

9. Nitao, J.J., "Reference Manual for the NUFT Flow and Transport Code, Version 1.0," . UCRL-ID-113520 Lawrence Livermore National-Laboratory, Livermore, CA (1995).

10. Peters, R.R., E.A. Klavetter, I.J. Hall, S.C. Blair, P.R. Hellers, and G.W. Gee, "Fracture and Matrix Hydrologic Characteristics of Tuffaceous Materials from Yucca Mountain, Nye County, Nevada," SAND84-1471, Sandia National Laboratories, Albuquerque, NM (1984). 
Technical Information Department - Lawrence Livermore National Laboratory University of California - Livermore, California 94551

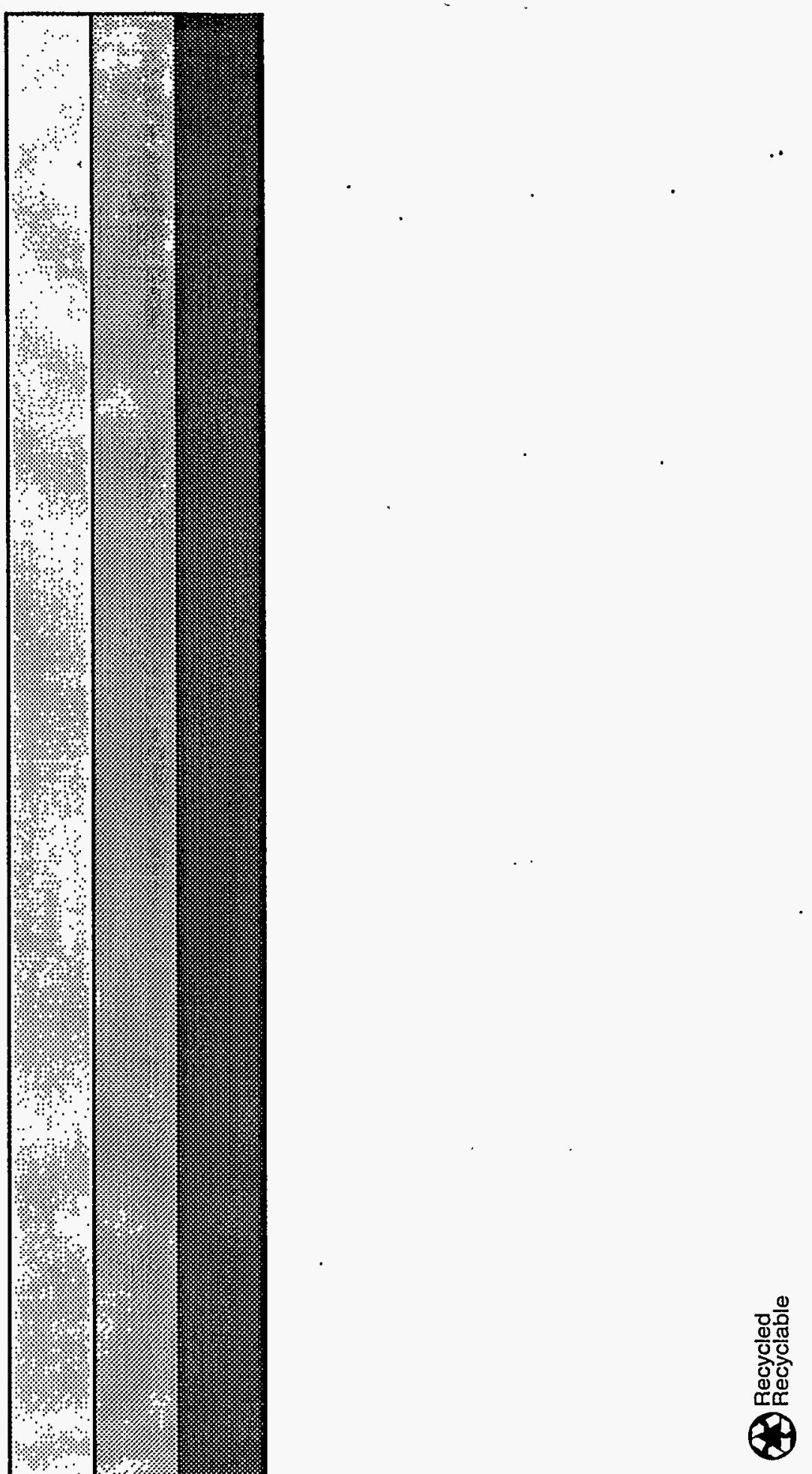

